\title{
A SINDICALIZAÇÃO DOS PROFISSIONAIS DE EDUCAÇÃO FÍSICA NO BRASIL
}

\author{
Antonio Augusto Bonatto Barcellos, Universidad de Salamanca - USAL, Salamanca- \\ Espanha \\ Alberto de Oliveira Monteiro, Universidade Federal do Rio Grande do Sul-UFRGS, \\ Porto Alegre, Rio Grande do Sul-Brasil \\ Luiz Roberto Nunes Padilla, Universidade Federal do Rio Grande do Sul - UFRGS, \\ Porto Alegre, Rio Grande do Sul - Brasil
}

\section{RESUMO}

O presente trabalho teve como propósito estudar a sindicalização dos profissionais de Educação Física e suas particularidades a partir da legislação brasileira e da ótica do direito do trabalho. O método de pesquisa utilizado foi a pesquisa bibliográfica e a redação seguiu o método dedutivo onde partimos de questões gerais sobre $o$ sindicalismo e a Educação Física até culminar com as questões mais específicas sobre a sindicalização dos profissionais de Educação Física. A partir de uma intensa pesquisa bibliográfica trouxemos uma contextualização histórica da Educação Física e histórica e jurídica do sindicalismo. Em relação ao tema da sindicalização dos profissionais de Educação Física abordamos os conceitos de categoria e os campos de atuação profissional. Finalmente, concluímos que os Profissionais de Educação Física constituem uma Categoria Profissional Diferenciada para fins sindicais.

Palavras-Chave: Sindicalização; Sindicatos; Educação Física; Profissão; Profissionais; Brasil.

\section{THE PHYSICAL EDUCATION PROFESSIONALS TRADE UNION'S IN BRAZIL}

\begin{abstract}
This paper intends to study some aspects about the trade union of the Physical Education professionals through the brazilian law and labor rights vision. The research method utilized was the bibliographic review and the style of writing followed the deductive method broaching general questions about the Physical Education and trade unions until more specific theme like the trade unions of the Physical Education professionals. To reach the goal an intense bibliographic review was made on the doctrine about the subject. We brought the historical conformation and the historical and juridical conformation of trade unions. Related to the trade unions of Physical Education professionals we broached the category and work areas concepts. Finally, we could conclude that Physical Education professionals effectively constitutes and differenced professional category around which the professionals can form a trade union.
\end{abstract}


Key-Words: Trade Union; Formation; Physical Education; Profession; Professionals; Brazil.

\section{LA SINDICACIÓN DE LOS PROFESIONALES DE EDUCACIÓN FÍSICA EN BRASIL}

\section{RESUMEN}

El presente trabajo tuvo como propósito estudiar la sindicación de los profesionales de Educación Física y sus particularidades a partir de la legislación brasileña y la óptica del derecho laboral. El método de investigación utilizado fue la investigación bibliográfica y la redacción ha seguido el método deductivo donde hemos empezado desde cuestiones más generales alrededor del sindicalismo y de la Educación Física hasta culminar con cuestiones más específicas sobre la sindicación de los profesionales de Educación Física. Desde una intensa investigación bibliográfica hemos traído el marco histórico de la Educación Física y histórico y jurídico del sindicalismo. Con relación al tema de la sindicación de los profesionales de Educación Física abordamos los conceptos de categoría y los campos de actuación profesional. Finalmente, hemos concluido que los profesionales de Educación Físicas constituyen una Categoría Profesional Diferenciada para fines sindicales.

Palabras-Clave: Sindicación; Sindicatos; Educación Física; Profesión; Profesionales; Brasil. 


\section{INTRODUÇÃO}

No presente trabalho buscamos investigar os principais aspectos e variáveis sobre a sindicalização dos Profissionais de Educação Física no Brasil. Desenvolveremos a tarefa posta sob a ótica da legislação brasileira e de conceitos de direito coletivo do trabalho.

Estudar o sindicalismo associado a todas as variáveis e históricas discussões no campo da Educação Física parece ser um assunto interessante e útil. Existe pouca bibliografia no Brasil sobre o assunto, concretamente sobre a sindicalização de profissionais de Educação Física em uma primeira pesquisa não se encontrou nenhum livro ou artigo científico centrado no tema.

A partir da regulamentação da profissão em 1998 é verdade que a Educação Física vive uma nova realidade, a par de algumas opiniões contrárias. Discutiremos questões sobre a formação histórica da Educação Física brasileira até o momento atual e também a organização sindical brasileira de modo a possibilitar a discussão da sindicalização no contexto legislativo brasileiro atual.

\section{A EDUCAÇÃO FÍSICA BRASILEIRA}

A Educação Física brasileira, desde sua gênesis, a finais do século XVIII, passou por muitas modificações. Apontamos como início da Educação Física, senão ainda de fato brasileira, pelo menos afetando a população, principalmente os tratados e orientações para a saúde física do povo português, aplicáveis, naquele momento ao Brasil colônia. Na época, a Educação Física tinha um claro caráter sanitário, no sentido de promover a saúde e o vigor dos homens, principalmente, responsáveis pela defesa militar do reino e pelas explorações e conquistas. Todavia estava muito presente, na Europa, o ideal clássico de educação integral expresso na máxima romana do poeta Juvenal, mens sana in corpore sano. Por outro lado, a primeira expressão do conceito de educação integral em solo brasileiro se deu com os jesuítas e os índios nas missões do sul do Brasil, como destaca Penna Marinho. ${ }^{1}$

Por outro lado, no período imperial, já pós-independência, começava a tomar corpo uma verdadeira preocupação com a educação (e consequentemente a Educação Física) da juventude brasileira. Durante a fase imperial diversas medidas são tomadas no sentido de implementar a Educação Física nas escolas a exemplo da criação da escola primária superior do Rio de Janeiro em cujo conteúdo curricular estavam a ginástica, equitação, natação, lutas e danças. Uma das primeiras obras sobre o assunto surge logo após a proclamação da independência, em 1828, intitulada como Tratado de Educação FísicaMoral dos meninos de autoria de Joaquim Jerônimo Serpa. A partir desta primeira obra, 
que de certa maneira inaugurou a produção científica brasileira sobre o assunto foram publicadas diversas outras. Outro documento da época trata-se do Decreto $\mathrm{n}^{\mathrm{o}}$ 8.025/1881 prescrevendo a ginástica como componente obrigatória do curso normal. ${ }^{2}$ Nas décadas de 1860 e 1870 foram fundadas no Brasil algumas das primeiras agremiações esportivas a exemplo da Sociedade Ginástica de Porto Alegre (1867), Clube Ginástico Português (1868) e o Clube Guanabarense (1874). O período imperial também foi a época que ficou marcada pelos pareceres de Rui Barbosa, talvez o mais célebre dos juristas brasileiros, o qual ficou conhecido como o "pai da Educação Física”. Seus pareceres recomendavam a adoção da Educação Física como componente curricular no sistema escolar brasileiro e aportavam ideias consideradas muito à frente do seu tempo.

Segue-se, naturalmente, o período republicano, normalmente dividido pelos historiadores em diversas fases. Na primeira delas, chamada de primeira república, período compreendido da proclamação (1889) até 1930, aproximadamente. É um lapso temporal marcado pela introdução e regulamentação de diversos desportos no país, a maioria deles novos e que acabam por difundir-se e conquistar adeptos. Também é nesta época que ocorre a implantação, no Brasil, da Associação Cristã de Moços (ACM) que traz ao Brasil as doutrinas ginásticas da escola alemã e acaba por desempenhar um importante rol na disseminação e desenvolvimento do esporte. ${ }^{3} \mathrm{Na}$ primeira década do século XX foi criada a primeira escola especializada na Educação Física. Tal escola pertencia a força policial do Estado de São Paulo. A Educação Física andou lado a lado com a evolução das instituições militares e, nos primeiros anos da república as duas maiores influências foram médico-higienistas e militares. No princípio do século também debutou uma das primeiras publicações especializadas a "Revista Brasileira de Educação Física”.

A segunda república e o período militar não foram especialmente pródigos com relação às inovações no campo da Educação Física. Sem embargo, se pode apontar alguns acontecimentos relevantes do período. Uma das legislações da segunda república é a Lei de Diretrizes e Bases de 1961 que a propósito de regular a educação na verdade tratava somente da organização escolar disciplinando um sistema educativo que já estava implantado como assevera Dermeval Saviani. ${ }^{4}$ De outra banda, as concepções de Conexões: revista da Faculdade de Educação Física da UNICAMP, Campinas, v. 13, n. 3, p. 146-174, jul./set. 2015. ISSN: $1983-9030$ 
educação estavam intimamente ligadas com a preparação do homem para o trabalho e não com uma concepção holística de educação. Nesse contexto, se lançava mão da Educação Física como um elemento de preparação da futura mão de obra, ajudando na manutenção de seu vigor físico. A Educação Física era apresentada como um tipo de saber totalmente empírico no qual unicamente havia que "fazer por fazer". 5 Outro acontecimento da época é o Diagonóstico sobre a Educação Física e os Desportos, publicado em 1971, por Lamartine Pereira da Costa, o qual possibilitou uma reflexão sobre os desportos no Brasil, fomentando a criação de uma política nacional de desportos brasileira. ${ }^{2}$ Os governos militares, a seu turno, viram no esporte um ótimo instrumento para alavancar o País. O acesso ao esporte para as camadas mais pobres seria uma forma de demonstrar o progresso social do País bem como servia também como instrumento de afirmação da nação no plano internacional. Os bons momentos esportivos foram aproveitados para insuflar sentimentos de orgulho e patriotismo na população. ${ }^{6}$ Cabe ressaltar que Educação Física e esporte, ainda que possuam muito em comum, não são sinônimos. Assim que, a despeito dos avanços no campo esportivo, no que tange à Educação Física o período não foi demasiado pródigo.

Segue-se o período da chamada Nova República, período imediatamente posterior ao regime militar que marca a transição ao estado democrático de direito e que perdura até os dias atuais. Segundo Tubino, ${ }^{2}$ o fim do regime militar marca uma nova forma de enxergar o desporto no país, baseado, principalmente, nas acepções de desportoeducação, desporto-participação e desporto-performance. Ainda, o momento de elaboração de uma nova constituição era propício para elevar o desporto ao patamar constitucional o que afinal se levou a cabo e hoje se consubstancia no artigo 217 da Carta Magna com algumas referências em outros artigos. ${ }^{7}$ Já especificamente em relação à Educação Física, o principal acontecimento do período foi o Parecer n ${ }^{\circ}$ 215/87 e a Resolução n ${ }^{\circ}$ 03/87 ambas do Conselho Federal de Educação os quais acabaram por criar os cursos de bacharelado em Educação Física. A partir de então, o Conselho transferiu para as instituições de ensino superior a responsabilidade pela elaboração dos currículos mínimos dos cursos. É importante destacar que já na época algumas vozes se insurgiram contra essa divisão entre licenciatura e bacharelado, especialmente pelo bacharelado ser menos abrangente que a licenciatura. Para Faria Júnior, ${ }^{8}$ por exemplo, o bacharel é sempre um generalista, enquanto o licenciado é um especialista, justamente 
em ensino escolar. Essa discussão acerca da profissão dos graduados em Educação Física, importantíssima para nosso objeto de estudo, permeou o período do final do regime militar e início da nova república. A discussão trazia à tona o problema da profissão do educador físico e o mercado de trabalho. Além disso, a recente afirmação da Educação Física como campo de conhecimento científico acabou por acirrar mais ainda as diferenciações entre o bacharel e o licenciado e criando novas denominações como ciência da motricidade humana ou ciência do desporto. ${ }^{9}$

A profissionalização continuou a ser um tema recorrente a partir da promulgação da chamada "Lei Zico" (Lei no 8.672/93), nascida como uma esperança de regulamentação reconhece a vertente profissional do desporto e o reafirmava, no mesmo sentido da Constituição Federal, como manifestação cultural e direito de todos. Logo na sequência da década de noventa, precisamente nos anos de 1996 e 1998, outros dois diplomas legais, a Lei de Diretrizes e Bases da Educação (1996) e a Lei do Profissional de Educação Física (1998) contribuíram para fomentar as discussões em torno à profissão relacionada aos bacharéis e licenciados em Educação Física. Assim, o fenômeno do profissionalismo passa a estar presente em todos os campos de intervenção do educador físico. Ainda, a chamada Carta Brasileira da Educação Física, também instituiu os órgãos de regulamentação e fiscalização profissional: o Conselho Federal de Educação Física (CONFEF) e os Conselhos Regionais de Educação Física (CREF's). ${ }^{10}$

Também no ano de 1998, foi promulgada a Lei Pelé (Lei 9.615/98) a qual o Congresso Nacional arvorou à condição de Lei Geral do Desporto. Contudo, a Lei Pelé possui uma inegável inclinação à regulamentação do futebol. ${ }^{11}$ Embora aparentando uma maior preocupação social com o desporto, cuida do futebol e deixa todos aos demais ao desamparo.

Ao que se nota a partir deste brevíssimo resumo apresentado a Educação Física brasileira é uma teia complexa traçada entre a evolução social, política, educacional e das ciências da saúde e do desporto. Os enfoques e prioridades relacionados com a Educação Física foram mudando ao longo da história e evolução da sociedade brasileira.

A partir da década de 60, principalmente, a Educação Física passa por um fenômeno de Conexões: revista da Faculdade de Educação Física da UNICAMP, Campinas, v. 13, n. 3, p. 146-174, jul./set. 2015. ISSN: 1983-9030 
esportivização. ${ }^{12}$ Este fenômeno faz com a Educação Física seja utilizada como uma ferramenta de promoção do desporto e este último como meio de promoção do Estado, interna e externamente.

A relação, por outro lado, de atividade física e educação remonta à antiguidade clássica onde a educação eficaz do corpo fazia parte de um ideal de educação integral e formação do cidadão grego. A paidéia grega, caminho para a excelência, envolvia uma multiplicidade de esferas do ser humano e, muito especialmente, aquelas relacionadas ao desenvolvimento do corpo. ${ }^{13}$

O viés pedagógico da Educação Física é muito forte. Educar o corpo é mais palpável, é visível e sensorial. Justamente por isso, sempre se buscou o liame entre a educação da mente através do corpo. Nesta linha também pensa, por exemplo, Foucault, ${ }^{14}$ para quem a pena corporal (aprisionamento do corpo) tem a função de educar a psique. Assim, o trabalho do educador físico também é um educar em sentido lato, e tende-se a enxergar o licenciado em Educação Física como professor, esteja onde estiver.

Existem autores, a exemplo de José Maria Barros, há mais de uma vaticinando a mudança no mercado profissional da Educação Física com o surgimento de novas oportunidades de trabalho e a diversificação dos campos de atuação. Mais um ingrediente agregado no caldeirão efervescente que tem sido a Educação Física brasileira. Assim é a opinião de $\operatorname{Barros}^{10}$ para quem a preparação de professores para o ensino de primeiro e segundo graus tem recebido mais atenção do que outras oportunidades de trabalho na área. Além disso, o autor vê um assunto interessante e complexo, ao colocar a Educação Física como um campo a quem incumbe relacionar motricidade, desporto e as novas demandas sociais de prestação de serviços no campo de atividades físicas.

Como se pôde notar, parece ser inegável que a Educação Física e os profissionais com ela atuantes, evolucionaram de maneira acentuada, ao menos nas duas últimas décadas. Novas oportunidades, novos postos de trabalho, diversificação de atividades e constante adaptação são características marcantes do período. Encontrar o fio condutor desta identidade em constante transformação e poder desconstruí-la, revelar sua estrutura e Conexões: revista da Faculdade de Educação Física da UNICAMP, Campinas, v. 13, n. 3, p. 146-174, jul./set. 2015. ISSN: $1983-9030$ 
acompanhá-la de perto parecem ser desafios válidos. Por seu turno, os campos de atuação e a identidade dos trabalhadores da área de Educação Física são elementos extremamente importantes quando tratamos da questão da sindicalização, como veremos no tópico seguinte.

\section{ALGUNS ELEMENTOS SOBRE SINDICATOS E SINDICALISMO NO BRASIL}

O sindicalismo é um movimento que, ao largo da história moderna, tem acompanhado as mudanças sociais e tem estreita relação com o sistema econômico, a política e as relações de trabalho, nestas também incluída a luta/oposição de classes consubstanciada na alteridade empregados versus empregadores. Todo este contexto, aliado à já vista complexidade da Educação Física no campo do trabalho, fornece-nos um excelente desafio: conjugar ambos os temas. Nas linhas seguintes, fornecemos um breve panorama do sindicalismo no Brasil.

\section{Sindicalismo no Mundo}

O próprio termo sindicato, etimologicamente, deriva do latim sindicus, por sua vez derivado do grego syndikayos e poderia ser traduzido como aquele que representa uma coletividade, a mesma acepção do síndico, tão conhecido nos condomínios residenciais e comerciais. ${ }^{15}$ Muitos autores apontam a origem do sindicalismo nas corporações de ofício da idade média e outros ainda retrocedem à antiguidade apontando remotos tipos de associação presentes nas civilizações grega, egípcia, romana e chinesa. ${ }^{16}$

Alguns outros, como Arion Sayão Romita ${ }^{17}$ e José Marthins Catharino, ${ }^{18}$ apontam as raízes do movimento sindical contemporâneo na revolução industrial e nas alterações provocadas por ela no seio social e nas relações de trabalho. A seu turno, Orlando Gomes e Elson Gottschalk ${ }^{19}$ assinalam que, embora existam semelhanças e pontos de congruência entre as corporações de ofício e os sindicatos atuais, as entidades são bastante diferentes. Segundo os últimos autores, as corporações de ofício defendiam os interesses da categoria dos mestres frente o consumidor, regulando os preços, a oferta de produtos e os modos de produção. O sindicato atual, por sua vez, é um instrumento de equilíbrio de força no jogo de interesses opostos entre os patrões e os empregados, 
mesmo que os interesses do empregador normalmente estejam opostos aos interesses da classe consumidora de uma maneira geral.

É inegável, de outra banda, que na Grécia, Roma e Egito já se pode vislumbrar a existências de certos tipos de associativismo. O próprio Aristóteles ${ }^{20}$ eternizou a frase em que afirma ser o homem um "animal social", pelo que necessita estar inserto em um grupo ou comunidade. Em Roma existiam, também, os "colégios" os quais reuniam os homens segundo suas artes e ofícios cumprindo uma determinação legal. Tratava-se de uma verdadeira divisão da população segundo artes e ofícios. Os colégios mediavam a relação de determinado grupo de indivíduos com o estado. ${ }^{21}$

Em época posterior, surge, fundamentalmente entre os povos germânicos e saxônicos, o sistema de guildas. As guildas possuíam de início, finalidades de reunião, companheirismo, lealdade e assistência mútua. Contudo, a partir do século X, passaram a apresentar finalidades políticas com o aparecimento de guildas mercantis e guildas de ofícios. ${ }^{27}$ Tais organizações (guildas) obtiveram um imenso poder político e econômico durante a idade média com vultosos pagamentos de impostos ao estado e, em contrapartida, obtiveram o monopólio do mercado, regulando os preços, a produção e as autorizações para que alguém pudesse exercer a profissão.

Tal sistema vigorou com sucesso até o advento da revolução francesa. O liberalismo exacerbado, uma das bandeiras da revolução, não admitia a existência de organismos políticos que intermediassem a relação do indivíduo com o estado. Qualquer associação, não importa qual fosse não deveria estar acima do homem. Começa então a decadência do sistema de guildas que seria seguida, logo após, pela revolução industrial.

A revolução industrial, somada à revolução francesa e à independência dos Estados Unidos, trouxe profundas mudanças na ordem social. $\mathrm{O}$ elemento trabalho e os trabalhadores passam a ter uma importância fundamental no novo sistema. Em oposição ao regime escravista ou corporativo vigentes até então, as revoluções e declarações de direitos humanos que se seguiram pregavam uma total e incondicional liberdade do homem, inclusive quanto ao trabalho. Passa-se a uma condição de liberdade total no estabelecimento dos contratos entre patrão e empregado. A liberdade excessiva acaba 
por conduzir a toda sorte de abusos onde, normalmente, os trabalhadores eram as vítimas.

A exploração sem limites do trabalho humano, exceto pelos limites impostos pelo esgotamento total das forças do empregado produz duas diferentes reações. A primeira delas tem que ver com a percepção, de parte dos trabalhadores de que deveriam se unir em prol de interesses comuns relacionados ao trabalho. E a segunda é que os estados nacionais reagem para intervir na relação capital/trabalho de modo a regular a estipulação do contrato de trabalho, dada a importância do tema para a ordem social.

A intervenção do estado nas relações de trabalho propicia um período de profunda confusão entre os deveres sindicais e estatais, além de uma promiscuidade de interesses entre política e sindicalismo. Tal situação culmina no período posterior à segunda guerra mundial onde as organizações internacionais e, entre elas, a Organização Internacional do Trabalho (OIT) pregam a liberdade de associação e a liberdade sindical. São do ano 1948 a Declaração Universal dos Direitos do Homem e também a convenção número 87 (oitenta e sete) da OIT determinando a implantação da liberdade sindical plena. Em suma, o surgimento e evolução de um fenômeno como o sindicalismo certamente não possui uma ou outra origem definida. O movimento sindical atual é a culminação de um longo processo sócio-histórico com diferentes e numerosas variáveis. ${ }^{23}$

\section{Sindicalismo no Brasil}

No Brasil, guardadas as devidas proporções, o movimento sindical seguiu as tendências mundiais. Existem alguns registros que dão conta, inclusive, da existência, no território brasileiro, de algumas espécies de corporações de ofício, com algumas semelhanças em relação àquelas da idade média. Sem embargo, inspirada nas tendências liberais mundiais, nossa primeira constituição, de 1824, proibia a criação de corporações de ofício. Outrossim, já no início do século XX, a Igreja Católica, na esteira da Encíclica Rerum Novarum, ${ }^{24}$ do Papa Leão XIII, passou a incentivar a mutualidade operária. É justamente nessa época que surgem no Brasil, as primeiras associações de trabalhadores como, por exemplo, a Liga de Resistência dos Trabalhadores em Madeira (1901), a Liga dos Operários em Couro (1901) e a Liga das Costureiras (1906). ${ }^{25}$ 
Em 1907, foi promulgado o decreto $\mathrm{n}^{\circ} 1637$, que autorizou a formação de sindicatos por todos os trabalhadores. Nesta fase, ainda incipiente, os sindicatos que se formaram tinham pouco ou nenhum poder de pressão. Aponta-se que os primeiros líderes sindicais teriam sido alvo de perseguição por parte de empregadores e governantes, minando a combatividade sindical no período. Já em 1931 foi lançado o Decreto n 19.770, que organizava o trabalho e as instituições sindicais brasileiras. Em seu bojo estavam insertas regras que preconizavam uma profunda dependência e controle dos sindicatos pelo estado e também a regra do sindicato único.

A carta magna de 1934, concebida sob ideais liberais, anulou a unicidade e estabeleceu marcos de autonomia e pluralidade. Contudo, a constituição foi novamente alterada em 1937, com a outorga de uma carta ditatorial que vinculou novamente os sindicatos ao governo e revogou os avanços nos campos da autonomia e pluralidade instituindo uma situação que permanece até os dias atuais. A Consolidação das Leis do Trabalho em vigor foi promulgada também no mesmo período, precisamente em 1943, inspirada na Carta del Lavoro de Mussolini. ${ }^{26}$

\section{Organização Sindical Brasileira}

Aqueles leitores não tão habituados ao direito coletivo do trabalho e o assunto dos sindicatos necessitam, principalmente, uma pequena noção de como funciona a organização sindical brasileira. Para isso, vale lembrar, como já dito, que enquanto a Consolidação das Leis do Trabalho é de 1943, a Constituição Federal é bastante posterior (1988). A norma constitucional tem prevalência sobre as demais, assim, aqueles dispositivos que estão em desacordo com a Carta Magna são tidos por "não recepcionados", ou seja, ficam já sem validade no ordenamento jurídico. Desta feita, o sincretismo resultante da justaposição das legislações cria o contexto da organização sindical brasileira, com todas as suas vicissitudes.

O sistema sindical brasileiro está previsto nos artigos 511 e seguintes (até o 577) da Consolidação das Leis do Trabalho e também no artigo $8^{\circ}$ da Constituição Federal. Adotaremos a sistemática de comentar os postulados mais importantes na ordem em que aparecem na legislação.

Conexões: revista da Faculdade de Educação Física da UNICAMP, Campinas, v. 13, n. 3, p. 146-174, jul./set. 2015. ISSN: 1983-9030 
É importante ressaltar, de início, que a Constituição Federal consagrou o princípio de não intervenção estatal nos sindicatos. Ao Estado fica vedado intervir no funcionamento e organização dos sindicatos sempre que estes cumpram os requisitos mínimos legais. $\mathrm{O}$ Estado tampouco pode negar o registro de sindicatos novos que cumpram a legislação. Destarte, os artigos 512 e 515 da Consolidação, os quais estabeleciam exigências para o reconhecimento e investidura sindical, podem ser tidos como tacitamente revogados a partir da nova ordem constitucional. Logo após, a CLT apresenta a polêmica regra da unicidade sindical segundo a qual somente pode existir um sindicato por categoria e por base territorial mínima. Retomaremos em momento posterior a discussão sobre a unicidade sendo, de momento, suficiente o conceito acima.

A propósito, a estrutura sindical brasileira é piramidal e confederativa. Na base da pirâmide estão os sindicatos com bases territoriais municipais, intermunicipais ou estaduais. No meio, temos as federações, com bases territoriais estaduais ou regionais. Por fim, no topo da pirâmide, estão as confederações, entidades representativas da categoria em nível nacional. São necessários ao menos 05 (cinco) sindicatos para a criação de uma federação e ao menos 03 (três) federações para a criação de uma confederação. Assim, o gênero "entidade sindical" engloba diferentes espécies de entidade nos vários níveis hierárquicos: sindicatos, federações, confederações e, desde 2008, também as centrais sindicais.

Outro ponto que merece destaque é que, como regra, os sindicatos são formados de acordo com a categoria econômica do empregador, de modo que haja uma paridade entre o sindicato patronal e o sindicato obreiro. Assim pontua Homero da Silva: $:^{279}$

Assim, por exemplo, integram o sindicato dos metalúrgicos quase todos os trabalhadores da indústria metalúrgica, ainda que ali não exerçam atividade de metalurgia, mas de compras, vendas, divulgação de produtos, limpeza, assessoria e assim por diante, ressalvadas as categorias ditas diferenciadas $[\ldots]$

O artigo 511 celetista, em seu parágrafo único, traz duas grandes hipóteses de reunião de trabalhadores para a formação de um sindicato. A primeira diz com trabalhadores que apresentam similitude de condições de vida oriundas da profissão ou trabalho em comum. Já a segunda refere-se aos trabalhadores com condições de emprego na mesma atividade econômica ou atividades conexas ou similares.

Conexões: revista da Faculdade de Educação Física da UNICAMP, Campinas, v. 13, n. 3, p. 146-174, jul./set. 2015. ISSN: 1983-9030 
Entretanto, a questão da categoria é justamente o cerne do presente estudo e será analisada de maneira pormenorizada mais adiante, deixando-a de lado neste momento. Persistem ainda muitas interessantes questões sobre a organização sindical. Só o tema da organização sindical poderia render muitas monografias, cinjamos-nos um pouco nas prerrogativas e funções das entidades sindicais, as quais acabam por constituir um verdadeiro binômio direito/dever de todas elas.

\section{Questões básicas sobre liberdade e unicidade sindical}

Os temas da liberdade e unicidade sindical são interessantíssimos e necessitam, ao menos, de uma rápida abordagem. Comentaremos primeiro sobre a liberdade sindical e depois sobre unicidade já que, para muitos, a questão da unicidade estaria inserida em um dos aspectos da liberdade sindical.

Para a maior parte dos doutrinadores brasileiros a liberdade sindical é elevada à condição mesma de princípio informador do sistema sindical. Tal acepção parece ser a mais correta como também parece acertada sobre a liberdade sindical ser um direito fundamental do qual são titulares trabalhadores e empregadores.

Os autores Nascimento e Russomano trazem diferentes enfoques para explicar a liberdade sindical. O primeiro a vê sob os prismas metodológico e conceitual. Para o plano metodológico a liberdade serviria como um filtro de interpretação para o restante das normas relativas à organização sindical e no plano conceitual estariam as diversas manifestações mesmas da liberdade e suas dimensões. Russomano, a seu turno, aponta a liberdade como um complexo de três diferentes institutos lembrando um triângulo equilátero. Em cada um dos lados do triângulo estaria o direito à sindicalização livre, à autonomia sindical e à pluralidade sindical.

Um dos lados do triângulo, a liberdade de associação (inserida no conceito de sindicalização livre) não tem que ver somente com a permissão para existência e funcionamento dos sindicatos. A liberdade de associação plena engloba também o direito de filiar-se ou de se desligar das entidades sindicais a qualquer momento. Já a autonomia sindical tem a ver com autorregulação das entidades sindicais. Isto é, a 
liberdade de fixação dos estatutos, da destinação do patrimônio, das esferas e formas de atuação e a desvinculação de controles externos estatais ou paraestatais. ${ }^{28}$

Completando os lados do triângulo da liberdade sindical proposto está a liberdade sindical. Ao menos no Brasil, este é, de longe, o mais polêmico deles. Num regime de liberdade sindical plena é permitida uma pluralidade ilimitada de sindicatos em oposição ao atual sistema do sindicato único vigente no Brasil. No regime em vigor a liberdade de empregadores ou trabalhadores limita-se em filiar-se ou não ao sindicato que formalmente representa sua categoria já que, como vimos, somente pode existir um único sindicato por categoria profissional.

A verdade é que a situação brasileira é sui generis no caso da liberdade sindical. Ainda que a constituição "cidadã" refira à liberdade sindical a mesma repete o postulado de intervencionismo estatal e unicidade sindical presentes na constituição de 1937 a "polaca", um curioso paradoxo. Outro dos paradoxos causados pelo sistema sindical brasileiro é a situação do Brasil perante a Organização Internacional do Trabalho - OIT. O Brasil é membro fundador e signatário da OIT. Tal organização aprovou, em 1948, a Convenção ${ }^{29}$ de número 087 que estabelece, em seu art. $2^{\circ}$, a total liberdade de criação e filiação às entidades sindicais. Desde então, após diversos governos, diferentes constituições, a norma internacional jamais foi ratificada para adquirir vigência no território brasileiro.

Tais questões sobre liberdade e unicidade tem reflexo em outros diversos pontos da questão sindical. Tais influências vão desde o reconhecimento sindical até o aparato oficial de custeio do sistema sindical passando pela representatividade dos trabalhadores.

\section{Negociação coletiva}

A negociação coletiva é uma das mais importantes funções sindicais e é tema central de praticamente qualquer assunto que envolva os sindicatos. Há quem diga que na negociação coletiva reside a essência do direito do trabalho enquanto outros afirmam que uma participação ativa e atuante na negociação coletiva favorece a que todo o contexto social se estruture de forma mais democrática. ${ }^{27}$ 
A origem da negociação coletiva pode ser localizada em momento anterior ao da gênese dos sindicatos tal qual os conhecemos hoje. Poder-se-ia situar sua origem com o nascimento das corporações de ofício medievais já que estas corporações estabeleciam de alguma forma, as condições e normas de trabalho. Também poder-se-ia fazer um paralelo com o surgimento dos primeiros movimentos grevistas onde a negociação, algumas vezes, foi a forma encontrada para pôr fim ao movimento paredista. É bom que se diga que a negociação coletiva e seus instrumentos como acordos e convenções são temas interdisciplinares por excelência. No estudo de tal tema convergem filósofos, sociólogos, antropólogos, economistas, civilistas, constitucionalistas e, por óbvio, estudiosos do direito laboral. A negociação coletiva parece ser um fato social complexo que acompanha os graus de industrialização e democratização de uma sociedade. O contrato individual de trabalho de certa forma antecede a negociação coletiva e esta última é uma forma de evolução natural para supressão das lacunas existentes naquele.

Convenção coletiva e acordo coletivo são institutos diferentes, é bom que fique claro. A principal diferença está na parte que ocupa o polo destinado aos empregadores. Na convenção coletiva o pacto é entabulado entre sindicatos, tanto de empregados quanto de empregadores. De outra parte, no acordo coletivo, o pacto é celebrado entre o sindicato dos trabalhadores e uma ou mais empresas da correspondente categoria econômica. Tal diferença está expressa no art. 611 da Consolidação das Leis do Trabalho. ${ }^{30}$

Outra das discussões envolvendo a negociação coletiva é a natureza jurídica dos instrumentos coletivos. Existem principalmente três teorias para definir a natureza jurídica do contrato coletivo: a civilista, a normativa e as teorias mistas. O jurista italiano Carnelutti define "o acordo coletivo como híbrido, com corpo de contrato e alma de lei". ${ }^{31: 116-117}$ E, com efeito, tal teoria, a mista, tem sido a mais aceita, pois o instrumento coletivo se assemelha ao contrato na sua elaboração, ao traduzir a vontade das partes e se parece às leis nos seus efeitos, que extrapolam as partes celebrantes e são extensivos a toda a categoria de trabalhadores. ${ }^{32}$ Também no tocante à negociação coletiva a ausência de uma liberdade sindical plena produz seus efeitos. A convenção de número 098 da OIT entende como indissociáveis a liberdade sindical e a evolução e desenvolvimento da negociação coletiva. 
No caso dos servidores públicos brasileiros, por exemplo, permitiu-se-lhes a sindicalização, mas foi-lhes negado o direito à negociação coletiva. Assim, a sindicalização dos servidores públicos pode ser apontada como pouco eficaz e pouco atuante já que somente lhes resta uma maneira de resolver os conflitos: a greve.

\section{Notas sobre greve}

Os historiadores apontam as origens da greve com o nascimento da grande indústria em momento posterior à revolução francesa onde, pela primeira, estabeleceram-se condições para o trabalho livre, ou seja, dissociado de fortes controles estatais. Inicialmente, a greve foi vista como um movimento para provocar a desordem e foi proibida, inclusive com sua penalização por diversos regimes. Nos países mais democráticos e desenvolvidos a greve se afirmou como um direito dos trabalhadores.

No Brasil a greve é um direito constitucionalmente assegurado desde a constituição de 1946. ${ }^{33}$ A greve também jogou um papel historicamente importante na afirmação da autonomia do direito do trabalho em face de outros ramos do direito. A greve também já se prestou e presta, até hoje como veículo de polêmicas e objeto de estudos. Pudera já que a mesma se trata de instituto jurídico no qual os empregados tem o direito de causar prejuízos ao empregador.

O conceito de greve, ainda que possua muitas divergências, poderia ser apontado como "a cessação coletiva e voluntária do trabalho, decidida por sindicatos de trabalhadores assalariados de modo a obter ou manter benefícios ou para protestar contra algo". 34:1033 Um conceito bastante parecido está insculpido no art. $2^{\circ}$ da Lei 7.783 de $1989^{35}$ que regulou o exercício do direito de greve assegurado pela novel constituição.

Várias teorias gravitam em torno do direito de greve. A sua natureza jurídica, legalidade entre outras coisas. Tantas polêmicas, divergências e teorias demonstram a multiplicidade de relações e institutos derivados de um único postulado: a sindicalização de trabalhadores. Mesclaremos agora os dois institutos, variados e multifacetados para discutir a sindicalização dos profissionais de Educação Física. 


\section{O CASO DA EDUCAÇÃO FÍSICA}

A Educação Física é uma área, como vimos, com muitas peculiaridades. É mesmo difícil traçar um paralelo com outras profissões no que toca à sindicalização. No Brasil, suas origens remetem ao período militarista e higienista e no mundo, ao controle corporal. Para Magnani ${ }^{36: 18}$ o corpo é

a primeira e mais disponível matéria-prima sobre a qual a sociedade por meio de técnicas e processos tão variados como tatuagem, escarificação, modelagem, mutilação, incrustações, coloração, ornamentação, vestuário, pintura, e muitos outros - imprime sinais que marcam diferenças, pertencimentos, exclusões, privilégios.

A Educação Física, em seus primeiros tempos, foi amplamente influenciada pelas ciências biológicas, uma tendência que até hoje pode ser verificada na grande carga de tais disciplinas nos cursos de formação. Ademais, não se pode esquecer que a Educação Física é mais do que estudo puro e simples do corpo. Qualquer corpo humano estará invariavelmente inserido em determinada cultura. ${ }^{37}$

Lado outro, sempre existiu uma forte associação entre a Educação Física e a escola. O controle sobre o corpo tem o significado de adaptar o indivíduo às práticas sociais vigentes. Exercer poder sobre o corpo tem a pretensão de educar a mente que seria atingida mediante o controle daquele. O corpo pode associar-se a aspectos que permitem ler características sociais e morais de alguém. O corolário lógico é que através das manifestações corpóreas poder-se-ia formar e reformar o homem. ${ }^{38}$ Tal é a razão da existência de uma multiplicidade de teorias e propostas pedagógicas centradas na educação do corpo. As propostas buscam civilizar o corpo e adequá-lo ao que a sociedade espera dele. O corpo é objeto e destinatário de intervenções de poder. ${ }^{39}$

A obra de Foucault já aqui referenciada representa o liame que conecta a Educação Física à escola, expressado no sentido de educação do corpo, de adequação social à ordem. Esse é apenas um dos grandes paradoxos da Educação Física. Nasceu das ciências biológicas, mas é fortemente ligada à escola na medida em que seus profissionais foram reconhecidos apenas como professores por décadas. Além disso, existe uma grande desvalorização dos profissionais no seio social. A atividade aparenta ser simples, não externando todo o necessário arcabouço de conhecimentos específicos necessários para seu correto desenvolvimento. Alguns autores argumentam ser essa a 
razão da "desprofissionalização" da área. ${ }^{40}$ Por isso, foi tão fácil identificar por tanto tempo o profissional de Educação Física como professor. Atualmente, isso não é mais possível devido ao grande número de mudanças nos cursos de formação e também nas demandas do mercado de trabalho.

Com a regulamentação legal da profissão em 1998, demanda já antiga da classe, criaram-se novas e diferentes perspectivas. Segundo alguns autores, a simples regulamentação teve o condão de distender imediatamente os campos de atuação profissional da Educação Física, antes voltados somente para a área escolar. A esfera escolar tornou-se insuficiente para atender as novas demandas sociais permeadas pela evolução tecnológica, industrialização, urbanização e profissionalização. Uma nova gama de atividades passa a atrair o graduado em Educação Física como a esportiva, atividades de melhoria da saúde e o lazer. Uma breve consulta ao Cadastro Brasileiro de Ocupações (CBO) vinculado ao Ministério do Trabalho mostra que houve um aumento imediato (após a regulamentação profissional) de $230 \%$ nas possibilidades de ocupação do graduado em Educação Física. Ainda, é de destacar, que das novas atividades, apenas um 30\% (trinta por cento) são atividades insertas no contexto escolar, enquanto os restantes $70 \%$ (setenta por cento) são ocupações em locais e atividades alheias ao contexto escolar. ${ }^{41}$

Existe uma necessidade óbvia de movimentar-se e foi necessária uma grande evolução dos profissionais e da oferta de atividades físicas, principalmente no contexto urbano. Se antes tínhamos o professor de Educação Física, agora temos o profissional de Educação Física. $^{42}$

Destarte, não existe dúvida em afirmar que a ação profissional em Educação Física e no desporto é bem mais ampla que o ato de ensinar movimentos ou promover a condição física. Áreas como administração, marketing, pesquisa, comunicação bem como o planejamento, execução e avaliação de programas de atividades físicas para as mais diversas clientelas é tendência cada vez maior dos profissionais da área de Educação Física. 


\section{Ponto de Interseção}

E então, de maneira invariável, o leitor atento deve questionar-se: como surge a interconexão de tais temas? Ou, qual é o fio conector da Educação Física e da questão sindical? Bem, a isso tentaremos responder.

Está claro que o campo profissional da Educação Física foi bastante ampliado. Em parte pelas demandas sociais e em parte pela própria evolução do campo do saber, a atuação se tornou mais complexa e com mais possibilidades de intervenção no mercado. Surgiu, no findar do século XX, uma lei que regulamentou a profissão. Tal regulamentação, como vimos, tem o condão de inserir a Educação Física no rol das Categorias Profissionais Diferenciadas, isto é, aqueles profissionais que dispõem de estatuto próprio e, em teoria, compartilham de uma mesma visão de mundo, das mesmas dificuldades, das mesmas aspirações.

Como nada é tão simples, vimos que Educação Física é uma profissão cheia de peculiaridades e que o sistema sindical brasileiro também tem lá suas características próprias que o tornam sui generis. A principal destas características é a questão da unicidade sindical que força a que exista somente um sindicato por categoria e base territorial.

Se a categoria é tão importante para a formação da entidade sindical ou em outras palavras é a "base sobre a qual se constrói o sistema sindical"43 e também, em linguagem mais informal se disse que se a categoria fosse o espírito, o sindicato seria corpo que permite sua vida encarnada. E então, dada a complexidade de ambos os contextos estudados, qual é a categoria ao redor da qual deveriam reunir-se os profissionais de Educação Física para constituírem um sindicato?

\section{A categoria, afinal}

É necessária a definição de alguns conceitos básicos para elucidar a questão da categoria para os profissionais de Educação Física. Precisaremos, novamente, de auxílio do Direito do Trabalho e da Antropologia. 
Algumas características podem ser apontadas como possíveis de destacar uma profissão em determinado campo de trabalho, são elas, a título de exemplo: habilidades especializadas, dedicação fundamental à pesquisa e instrução, função social exercida, período extenso de preparação e formação e a organização profissional. Outros poderiam dizer que a profissão é somente uma área que possua um corpo de conhecimentos exclusivo de onde derivariam as bases do exercício profissional e da instrução e formação dos futuros profissionais. ${ }^{44}$

O processo de delinear tais características seria o hábil a dizer qual ocupação pode ser considerada como uma categoria profissional distinta. Cabe ressaltar que a legislação brasileira atual não faz mais que dar pistas sobre qual seria o critério definidor de uma categoria profissional diferenciada resumindo a distinção em uma atividade que "apresenta condições de vida singulares". O conceito é demasiado amplo, tal qual o de categoria profissional que resultaria da "similitude de condições de vida oriunda da profissão ou trabalho em comum”.

Ainda uma distinção é necessária, a dos profissionais liberais. Uma das poucas definições que existe está em uma nota técnica do Ministério do Trabalho. Segundo ela os profissionais liberais são aqueles em condições de exercer sua profissão de forma autônoma ou como empregados, mas que estão legalmente habilitados, registrados nos respectivos conselhos profissionais após haverem atendido exigências técnicocientíficas e legais necessárias ao exercício profissional. A confusão entre profissão liberal e categoria profissional diferenciada é bastante comum. Para Sussekind ${ }^{45}$ e para Romita $^{46}$ os integrantes de uma determinada categoria profissional compartilham um sistema de relações sociais, possuem normas e standards aceitos pelo grupo que marcam as fronteiras de inclusão e exclusão, isto é, possuem uma cultura própria que permite identificar quem é e quem não é membro do grupo. ${ }^{47}$

Os profissionais de Educação Física parecem enquadrar-se perfeitamente no conceito de categoria profissional diferenciada. Possui um estatuto profissional próprio. Bem assim, possui um corpo de conhecimentos próprios e a existência de um processo formativo de curso superior organizado e necessário para o registro profissional no conselho regulador respectivo (com algumas exceções e anistias concedidas pela lei). 
Curiosamente, pouco ou quase nada foi escrito no Brasil sobre o assunto. Os principais livros sobre profissões regulamentadas, mesmo após mais de 15 (quinze) anos da promulgação da lei 9.696/98. Falam sobre o aeronauta, o atleta profissional, o advogado, o médico, o dentista, as secretárias, mas absolutamente nada sobre os profissionais de Educação Física.

Um dos principais motivos seja, quiçá, a impossibilidade de perceber o profissional de Educação Física dissociado da figura do professor. A profissão de professor está regulamentada pela própria Consolidação das Leis do Trabalho nos artigos 317 a 324. Alice Barros também parecia acometida de dúvidas ao escrever, no capítulo dedicado aos professores que, para ela, os instrutores de natação, ginástica, voleibol, musculação, futebol de salão, dança e outros do mesmo gênero não poderiam ser enquadrados como professores.

A argumentação da autora traduz uma dúvida presente inclusive no âmago do grupo de pessoas que se relaciona com a Educação Física nas suas mais variadas formas. A autora utilizou o exemplo dos instrutores de desportos em geral por ser o exemplo mais óbvio e latente ainda que pudesse ter utilizado outros como do instrutor da autoescola, de cursos de inglês, de cursos preparatórios para concursos ou para o vestibular e tantos mais possíveis de imaginar. ${ }^{48}$ Em teoria, todos poderiam se chamar professores. No entanto, discutimos a questão sindical e a normativa legal brasileira pela qual, segundo Homero Batista Mateus da Silva: ${ }^{49: 149}$

Embora todas essas semelhanças sejam verificáveis na prática, o legislador sempre se afastou desse conceito harmônico, priorizando a proteção sobre os professores da rede oficial de ensino, pública, particular, comunitária, confessional ou filantrópica (art. 20 da LDB), deixando-se ao desabrigo os demais sujeitos dos cursos extracurriculares.

Foi assim na CLT ('magistério em estabelecimentos particulares de ensino') e é assim na LDB ('professor como o profissional da educação básica e superior').

No Brasil, o pertencimento ou não à determinada categoria decorre da lei tendo em vista a unicidade sindical. Portanto, quem confere representatividade ao sindicato e vida à categoria é o Estado. Os trabalhadores brasileiros não podem, assim, optar pela categoria que lhes gostaria pertencer ou pelo sindicato que melhor lhes represente. Os trabalhadores podem, tão somente, escolher por filiar-se ou não ao sindicato oficial de Conexões: revista da Faculdade de Educação Física da UNICAMP, Campinas, v. 13, n. 3, p. 146-174, jul./set. 2015. ISSN: 1983-9030 
sua categoria. Em decorrência disso, parece que todo o profissional que exerça alguma das atividades elencadas pelo art. $3^{\circ}$ da Lei $9.696 / 98$ pertence, efetivamente à categoria dos educadores físicos.

\section{DESAFIOS DE SINDICALIZAÇÃO}

Na sociedade contemporânea é impossível negar a importância do sistema de sindicatos. O sindicalismo é elemento indispensável da vida de qualquer Estado que pretenda ser democrático. A Educação Física está bastante atrasada neste aspecto, como está a totalidade da nação em relação a outros países que já adotaram o regime de sindicalização livre e dão mais importância à negociação coletiva. Nosso modelo de sindicatos únicos está ultrapassado. Para Romita, ${ }^{50: 280}$

[...] o progresso das relações sociais depende da atuação esclarecida dos sindicatos, no desempenho da função que lhes é inerente e indelegável, de defender a dignidade do trabalho com base no espírito de solidariedade.

Os sindicatos também são uma ferramenta de pacificação social, aptos a auxiliar nos enfrentamentos e na canalização de pulsões sociais sem a intervenção do Estado. A Educação Física, enquanto um fenômeno cultural e social além do biológico, não pode estar alheia ao assunto, seja como corpo de profissionais, seja como área organizada do conhecimento humano.

O pertencimento a determinada categoria profissional, como já dito alhures, gera consequências ao trabalhador, independentemente de sua vontade. Tais consequências se produzem mesmo que o trabalhador não queira ou não conheça o sindicato representante da sua categoria. No caso de uma negociação coletiva, a mesma obriga a todos os trabalhadores e empregadores das categorias profissionais e econômicas representadas pelos sindicatos respectivos. Nos dizeres de Cassar" 34:1021 a "convenção coletiva tem aplicação para toda a categoria econômica (associados ou não) e profissional (associados ou não), representadas pelos sindicatos convenentes, naquela base territorial."

Para exemplificar imaginemos o Sindicato dos Profissionais de Educação Física do município "A" celebrando uma convenção coletiva com o Sindicato das Academias de Ginástica também do município “A”. Tal convenção poderia versar sobre salário 
mínimo normativo para a categoria (é claro, nunca inferior ao legal), jornada de trabalho (tempo de intervalo, por exemplo), adicionais vários, concessão de auxílio-alimentação, transporte, cestas básicas, enfim, uma variedade de temas. O disposto em tal convenção coletiva valerá para todos os Profissionais de Educação Física do município "A" e também para todas as Academias de Ginástica do município "A", tudo isso independentemente da manifestação de concordância destes ou mesmo de seu conhecimento sobre as cláusulas, participação nas negociações etc.

A questão sindical também possibilita a imposição, pelos sindicatos da contribuição sindical, que decorre de lei, a todos os membros da categoria. Esse efeito normativo é condicionado pela unicidade sindical e pelo princípio da isonomia.

A relevância do tema faz com que importantes e reconhecidos órgãos internacionais como a Organização das Nações Unidas (ONU) e a Organização Internacional do Trabalho (OIT) constantemente abordem e reforcem o assunto. ${ }^{51}$ Aliás, são ótimos indicadores dos níveis de desenvolvimento de uma determinada sociedade o grau de sindicalização, os níveis de negociação coletiva e a sindicalização livre.

A Educação Física, foi historicamente repleta de disputas e conflitos entre teorias e doutrinas. ${ }^{52} \mathrm{O}$ maior desafio aos profissionais é deixar as diferenças de lado e ocupar-se mais do tema sindical, em prol de melhores condições para todos.

\section{CONSIDERAÇÕES FINAIS}

Ao final de um estudo soem surgir mais dúvidas do que respostas o que é reforçado pela polêmica envolvendo o tema sindical e, em especial, àquele relacionado também com a Educação Física. Note-se: uma efetiva liberdade sindical, onde cada trabalhador pudesse escolher livremente o sindicato de sua escolha ou mesmo não escolher nenhum, solucionaria apenas alguns problemas. Persistiriam as dúvidas e os anseios sobre a conformação da Profissão dos graduados em Educação Física e seus contornos, descobrir até onde vai a fronteira de pertencimento à profissão seria uma delas.

No Brasil, a artificialidade do conceito de categoria as reduz a mera formalidade para a formação dos sindicatos. A discussão das questões em torno aos limites de inclusão e Conexões: revista da Faculdade de Educação Física da UNICAMP, Campinas, v. 13, n. 3, p. 146-174, jul./set. 2015. ISSN: $1983-9030$ 
exclusão de cada categoria profissional e o desenvolvimento de um espírito de grupo e sentido de pertencimento é válida inclusive em um contexto de liberdade sindical, não se vislumbrando em um futuro próximo no Brasil.

Em uma profissão tão dividida, com tantos campos de atuação e com tantos enfrentamentos é fácil os profissionais dividirem desvalorizando a profissão. A sindicalização e conscientização dos trabalhadores e empregadores pode ser um instrumento de melhoria das condições profissionais dos primeiros e mesmo de aumento de ganhos dos últimos. Neste sentido, esperamos haver contribuído com o esclarecimento de profissionais, estudantes e docentes.

Por fim, parece-nos que, a partir da promulgação da lei 9.696/98, a profissão de Educador Físico passou a ser considerada, com mais razão, uma categoria profissional diferenciada para fins sindicais. Os limites desta categoria e os artifícios utilizados para a criação de novos sindicatos dentro do marco legal brasileiro ainda persistem como dúvida a qual pretendemos dirimir em um futuro estudo com auxílio de outros métodos de investigação.

\section{REFERÊNCIAS}

${ }^{1}$ MARINHO, I. P. História geral da Educação Física. São Paulo: Cia. Brasil, 1980.

${ }^{2}$ TUBINO, M. J. G. O esporte no Brasil: do período colonial aos nossos dias. São Paulo: IBRASA, 1996.

${ }^{3}$ GAYA, A. MAZO, J. As associações desportivas em Porto Alegre, Brasil: espaço de representação da identidade cultural teuto-brasileira. Revista Portuguesa de Ciências do Desporto, Porto, v. 6, n. 2, p. 205-213, 2006.

${ }^{4}$ SAVIANI, D. Educação: do senso comum à consciência filosófica. São Paulo: Cortez, 1982.

${ }^{5}$ CASTELANi FILHO, L. Educação Física no Brasil: a história que não se conta. Campinas: Papirus, 1988.

Conexões: revista da Faculdade de Educação Física da UNICAMP, Campinas, v. 13, n. 3, p. 146-174, jul./set. 2015. ISSN: 1983-9030 
${ }^{6}$ OLIVEIRA, M. A. T. O esporte brasileiro em tempos de exceção: sob a égide da ditadura (1964-1985). In: PRIORE, M; ANDRADE, V. M. (Org.). História do esporte no Brasil: do império aos dias atuais. São Paulo: Ed. da UNESP, 2009. p. 387-416

${ }^{7}$ BRASIL. Presidência da República. Constituição Federal. 05 de outubro de 1988. Disponível em: <http://www.planalto.gov.br/ccivil_03/constituicao/constituicao.htm> Acesso em: 10 maio 2014.

${ }^{8}$ FARIA JÚNIOR, A. G. Professor de Educação Física, licenciado generalista. In: OLIVEIRA, V. M. (Org.). Fundamentos pedagógicos da Educação Física. Rio de Janeiro: Ao Livro Técnico, 1987, p. 11-33.

${ }^{9}$ SOUZA NETO, S. et al. A formação do profissional de Educação Física no Brasil: Uma história sob a perspectiva da legislação federal no século XX. Revista Brasileira de Ciências do Esporte, Campinas, v. 25, nº 2, p. 113-128, jan. 2004.

${ }^{10}$ BARROS, J. M. C. Educação Física, profissão regulamentada. Revista Brasileira de Ciências do Esporte, Campinas, v. 21, n. 2/3, p. 108-109, jan./maio 2000.

${ }^{11}$ PADILLA, L. R. N. Legislação desportiva comentada. Disponível em: <www.padilla.adv.br/desportivo> Acesso em: 01 maio 2012.

${ }^{12}$ RODRIGUES, L. L.; BRACHT, V. As culturas da Educação Física. Revista Brasileira de Ciências do Esporte, Campinas, v. 32, n. 1, p. 93-107, set. 2010.

${ }^{13}$ MONTEIRO, A. O. Desporto: da excelência a virtude, um caminho de vida para crianças, jovens e adultos. 2007. 497f. Tese (Doutorado em Educação Física) Faculdade de Desporto, Universidade do Minho, Portugal, 2007.

${ }^{14}$ FOUCAULT, M. Vigiar e punir: nascimento da prisão. Petrópolis: Vozes, 1987.

${ }^{15}$ SCHWARZ, R. G. Direito do trabalho. Rio de Janeiro: Elsevier, 2009.

Conexões: revista da Faculdade de Educação Física da UNICAMP, Campinas, v. 13, n. 3, p. 146-174, jul./set. 2015. ISSN: 1983-9030 
${ }^{16}$ SANTOS, L. A. M. A liberdade sindical como direito fundamental. São Paulo: LTr, 2009.

${ }^{17}$ ROMITA, A. S. Sindicalismo. São Paulo: LTr, 1986.

${ }^{18}$ CATHARINO, J. M. Tratado elementar de direito sindical. São Paulo: LTr, 1982.

${ }^{19}$ GOMES, O.; GOTTSCHALK, E. Curso de direito do trabalho. Rio de Janeiro: Forense, 2002.

${ }^{20}$ ARISTÓTELES. Política. Lisboa: Vega, 1998.

${ }^{21}$ VIANNA, S. O sindicato no Brasil. Rio de Janeiro: Olímpica, 1953.

${ }^{22}$ NASCIMENTO, A. M. Direito sindical. São Paulo: Saraiva, 1991.

${ }^{23}$ RUSSOMANO, M.V. Princípios gerais de direito sindical. Rio de Janeiro: Forense, 1998.

${ }^{24}$ IGLESIA CATÓLICA. Papa León XIII. Encíclica "rerum novarum": sobre la condición de los obreros/por el Sumo Pontífice León XIII con presentación de la Encíclica, un esquema de la misma, resúmenes y apéndice. Tortosa: Editorial Católica, 1932.

${ }^{25}$ NASCIMENTO, A. M. Compêndio de direito sindical. São Paulo: LTr, 2008.

${ }^{26}$ LIMA, L. T. Movimento sindical e luta de classes. São Paulo: Oliveira Mendes, 1998.

27 SILVA, H. B. M. Curso de direito do trabalho aplicado: direito coletivo do trabalho. Rio de Janeiro: Elsevier, 2009. v. 7. 
${ }^{28}$ DELGADO, M. G. Curso de direito do trabalho. São Paulo: LTr, 2009.

${ }^{29}$ ORGANIZAÇÃO INTERNACIONAL DO TRABALHO. Convenção no 87 de 1948 : liberdade sindical e proteção ao direito de sindicalização. Disponível em: < http://www.oit.org.br/content/liberdade-sindical-e-proteção-ao-direito-desindicalização > Acesso em: 08 jun. 2012.

${ }^{30}$ BRASIL. Presidência da República. Decreto-lei 5.452 de 1943. Disponível em: <http://www.planalto.gov.br/ccivil_03/decreto-lei/Del5452compilado.htm> Acesso em: 08 maio 2014.

${ }^{31}$ CARNELUTTI, F. Teoria del regolamento collettivo dei rapporti di lavoro. Padova: Antonio Milani, 1936.

${ }^{32}$ JORGE NETO, F. F.; P. CAVALCANTE, J. Q. Estudos dirigidos: direito do trabalho. São Paulo, LTr, 1999.

${ }^{33}$ SÜSSEKIND, A. et al. Instituições de direito do trabalho. São Paulo: LTr, 2005.

${ }^{34}$ CASSAR, V. B. Direito do trabalho. Niterói: Impetus, 2009.

${ }^{35}$ BRASIL. Presidência da República. Lei Federal $\mathbf{n}^{\mathbf{0}} \mathbf{7 . 7 8 3}$ de 1989. Disponível em: <http://www.planalto.gov.br/ccivil_03/leis/L7783.htm > Acesso em: 07 maio 2014.

${ }^{36}$ MAGNANI, J. G. C. Antropologia e Educação Física. In: CARVALHO, Y. M. C.; RUBIO, K. (Org.). Educação Física e ciências humanas. São Paulo: Hucitec, 2001. p. 17-26.

${ }^{37}$ DAOLIO, J. Antropologia Social e Educação Física: possibilidades de encontro In: CARVALHO, Y. M. C.; RUBIO, K. (Org.). Educação Física e ciências humanas. São Paulo: Hucitec, 2001. p. 27-38.

${ }^{38}$ REVEL, J. Os usos da civilidade. In: ARIÉS, P.; DUBY, G. (Org.). História da vida privada: da renascença ao século das luzes. São Paulo: Companhia das Letras, v. Conexões: revista da Faculdade de Educação Física da UNICAMP, Campinas, v. 13, n. 3, p. 146-174, jul./set. 2015. ISSN: $1983-9030$ 
3,1991. p. 169-209.

${ }^{39}$ SOARES, C. Imagens da retidão: a ginástica e a educação do corpo. In: CARVALHO, Y. M.; RÚBIO, K. (Org.). Educação Física e ciências humanas. São Paulo: Hucitec, 2001. p. $53-74$

${ }^{40}$ BETTI, M. Perspectivas na formação profissional. In: MOREIRA, W. W. (Org.). Educação Física \& esportes: perspectivas para o séc. XXI. Campinas: Papirus, 1992. p. 239-254.

${ }^{41}$ GALINDO, A. G. Mercado de trabalho e educação Física: um breve ensaio sobre os impactos da regulamentação profissional. In: SEMANA DO PROFISSIONAL DE EDUCAÇÃO FÍSICA, 2005, Macapá. Anais... Macapá: Secretaria Estadual de Desporto e do Lazer, 2005. p. 21-39.

${ }^{42}$ OLIVEIRA, A. A. B. Mercado de trabalho em Educação Física e a formação profissional: breves reflexões. Revista Brasileira de Ciência e Movimento, Brasília. v. 8 , n. 4 , p. $45-50$, set. 2000.

${ }^{43}$ BARROS, A. M. Curso de direito do trabalho. São Paulo: LTr, 2005.

${ }^{44}$ FARIA JÚNIOR, A. G. Perspectivas na formação profissional em Educação Física. In: MOREIRA, W. N. (Org.). Educação Física \& esportes: perspectivas para o séc. XXI. Campinas: Papirus, 1992. p. 227-238

${ }^{45}$ SUSSEKIND, A. Direito constitucional do trabalho. Rio de Janeiro: Renovar, 2004. ${ }^{46}$ ROMITA, A. S. Direito sindical brasileiro. Rio de Janeiro:, 1976.

${ }^{47}$ AGUIRRE BAZTAN, S. A. La cultura de las organizaciones. Barcelona: Ariel, 2004.

${ }^{48}$ BARROS, A. M. Contratos e regulamentações especiais de trabalho: peculiaridades, aspectos controvertidos e tendências. São Paulo: LTr, 2001. 
${ }^{49}$ SILVA, H.B.M. Curso de direito do trabalho aplicado: livro das profissões regulamentadas. Rio de Janeiro: Elsevier, 2009. v. 4. p. 149.

${ }^{50}$ ROMITA, A. S. A legislação trabalhista e os sindicatos. In: SILVESTRE, R. M.; NASCIMENTO, A. M. (Org.). Os novos paradigmas do direito do trabalho: Homenagem a Valentin Carrion. São Paulo: Fapesp, 1999. p. 280

${ }^{51}$ GÓIS, L. M. F. Princípios da negociação coletiva de trabalho. Justiça do trabalho, Porto Alegre, ano 26, n. 304, abr. 2009.

${ }^{52}$ SANTA'ANNA, D. B. Educação Física e História. In: CARVALHO, Y. M. ; RÚBIO, K. (Org.). Educação física e ciências humanas. São Paulo: Hucitec, 2001. p. 105-114.

Recebido em: 22 nov. 2014 Aceito em: 10 abr. 2015 Contato: antonio.barcellos@usal.es 